\title{
Crystalline characteristics of annealed AIN films by pulsed laser treatment for solidly mounted resonator applications
}

\author{
H. K. Lin ${ }^{1 *}$, Y. J. Huang ${ }^{1}$, W. C. Shih ${ }^{2}$, Y. C. Chen ${ }^{2}$ and W. T. Chang ${ }^{3}$
}

\begin{abstract}
AIN films were deposited on Si substrates using a reactive RF magnetron sputtering process and then the films were annealed by using different laser powers and wavelengths ( $355 \mathrm{~nm}, 532 \mathrm{~nm}$ and $1064 \mathrm{~nm}$ ). For all three laser systems, the (002) peak intensity was obviously improved following laser irradiation. The improvement in the crystalline property was particularly obtained in the AIN film processed at $355 \mathrm{~nm}$. In particular, given the use of the optimal laser power $(0.025 \mathrm{~W})$, the $(002)$ peak intensity was $58.7 \%$ higher than that of the as-deposited film. The resonant frequency and $3 \mathrm{~dB}$ bandwidth of a SMR filter with an unprocessed AIN film were found to be $2850 \mathrm{MHz}$ and $227.81 \mathrm{MHz}$, respectively. Following laser treatment with a wavelength of $1064 \mathrm{~nm}$ and a power of $0.25 \mathrm{~W}$, the resonant frequency changed from 2850 to $2858 \mathrm{MHz}$. Moreover, $3 \mathrm{~dB}$ bandwidth changed from 227.81 to $202.49 \mathrm{MHz}$ and the return loss of the filter reduced from 17.28 to $16.48 \mathrm{~dB}$. Overall, the results thus show that the frequency response of the SMR filter can be adjusted and the return loss reduced by means of laser treatment with an appropriate wavelength.
\end{abstract}

Keywords: Laser, Acoustic wave device, AIN, Annealing

\section{Introduction}

Acoustic wave devices are widely used in the wireless communication field. Surface acoustic wave filters (SAWFs) [1-3] and film bulk acoustic resonators (FBARs) [4-6] have attracted particular attention as a means of achieving high operating frequencies (exceeding gigahertz) in radio frequency (RF) communications. In realizing such devices, the acoustic wave is confined to resonate as a standing wave using either air gap isolated resonators or solidly mounted resonators (SMRs) [7-9]. SMRs typically consist of a Bragg reflector and a piezoelectric film sandwiched between two electrodes.

The performance of acoustic wave filters is highly dependent on the crystalline quality of the piezoelectric layer. Of the various piezoelectric materials available, single crystal aluminum nitride (AIN) is one of the most commonly used in the optoelectronic, sensor and

*Correspondence: HKLin@mail.npust.edu.tw

${ }^{1}$ Graduate Institute of Materials Engineering, National Pingtung

University of Science and Technology, Pingtung, Taiwan

Full list of author information is available at the end of the article wireless communication fields due to its wide bandgap $(6.2 \mathrm{eV})$, favorable thermal conductivity $(>100 \mathrm{~W} / \mathrm{mk})$ and high dielectric constant ( 8.5) [10-12]. AlN piezoelectric films can be deposited using various methods, including chemical vapor deposition (CVD) [13], reactive sputtering [14], molecular beam epitaxy (MBE) [15], and pulsed laser deposition (PLD) [16]. However, irrespective of the method used, the quality of the AlN film (and hence the device performance) is strongly dependent on the nitrogen concentration and the processing parameters [15]. Various studies have shown that the crystalline structure of AlN films can be improved through post-deposition plasma, laser, or rapid thermal annealing (RTA) treatment $[12,17,18]$. Lee also reported that an excellent return loss of the solidly mounted resonator-type film bulk acoustic wave resonator devices were observed after the post annealing process [19]. High crystallinity AlN films were obtained by modulating the growth temperature and thermal annealing conditions. High thermal annealing temperature and short annealing time further improve the crystallinity and also preserve the smooth surface [20]. For (10-1-3) and (11-22) AlN 
layers grown on m-plane sapphire, the crystal quality improved with increasing annealing temperature up to $1700{ }^{\circ} \mathrm{C}$ because the density of basal plane stacking faults reduced. These results indicate that the thermal annealing technique offers a new way of fabricating highly efficient semipolar UV LEDs on sapphire substrates [21]. Moreover, laser annealing has been applied in various fields, including active-matrix organic light-emitting diode (AMOLED), metallic glass thin films, complementary metal oxide semiconductor (CMOS), and thin film bulk acoustic wave (TFBAR) [22, 23]. Compared to these traditional annealing techniques, laser annealing has advantages including faster actuation response, rapidly cooling rate and controllable penetration depth into the substrate. It is beneficial for a uniform concentration, lower defect density and local heating area [24]. Cheng [25] reported that laser treatment results in an effective improvement in the c-axis preferred orientation of $\mathrm{ZnO}$ films and is thus beneficial in reducing the return loss of $\mathrm{ZnO}$-based longitudinal mode FBARs.

In the present study, the SMR device is consisted by Bragg reflector, AlN thin films and electrode. Firstly, the Bragg reflector is fabricated on Si substrate, and then the bottom electrode is fabricated on Bragg reflector through DC sputter combined with lithography process technology. Secondly, the AlN thin films are deposited on the bottom electrode using reactive RF magnetron sputter. Finally, top electrode is constructed on the AlN thin films by lithography process technology; the SMR device is then completed. The AlN films are then treated by laser irradiation using various laser powers and wavelengths. The effects of the laser processing parameters on the crystalline quality, optical transmittance, resonant frequency and return loss properties of the AlN films are then examined and compared.

\section{Experiment}

As shown in Fig. 1, the SMR devices fabricated in this study consisted of a Si substrate, a Bragg reflector, an AlN piezoelectric layer, bottom and top electrodes. The AIN film was deposited on the Si substrate using a reactive $\mathrm{RF}$ magnetron sputtering system with an $\mathrm{Al}$ target. The sputtering process was performed using a $\mathrm{N}_{2} /\left(\mathrm{N}_{2}+\mathrm{Ar}\right)$ flow of $60 \%$, a base pressure of $5 \times 10^{-7}$ Torr, and a working pressure of 10 mTorr. In addition, the substrate was maintained at a temperature of $300{ }^{\circ} \mathrm{C}$ and the sputtering power was set as $230 \mathrm{~W}$.

Following the deposition process, the AlN films were treated using three different laser systems, namely a near infrared laser (SPI G3) with a wavelength of $1064 \mathrm{~nm}$, a Green laser (Coherent MATRIX 532-7-30) with a wavelength of $532 \mathrm{~nm}$, and a UV laser (Coherent AVIA 3557000 ) with a wavelength of $355 \mathrm{~nm}$. In laser patterning

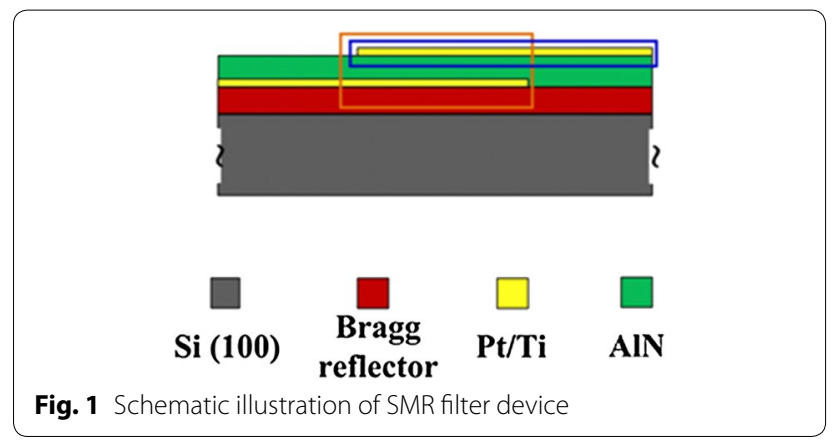

processes, the diameter of the laser spot, $\mathrm{D}_{0}$, can be calculated as

$$
D_{0}=1.22 \times\left(\frac{\lambda \times F}{n \times W_{d}}\right) \times M^{2},
$$

where $\lambda$ is the laser wavelength, $F$ is the focal length, $n$ is the refractive index of the working material, $W_{d}$ is the diameter of the incident laser beam, and $M^{2}$ is the laser quality factor. For the NIR laser, $M^{2}$ was equal to $1.3, F$ was $163 \mathrm{~mm}$, and $W_{d}$ was $7.2 \mathrm{~mm}$. Meanwhile, for the Green laser, $M^{2}, F$ and $W_{d}$ were equal to $1.3,330 \mathrm{~mm}$ and $5.8 \mathrm{~mm}$, respectively. Finally, for the UV laser, $M^{2}$ was equal to $1.3, F$ was $100 \mathrm{~mm}$, and $W_{d}$ was $3.5 \mathrm{~mm}$. The spot diameters for the three laser systems were thus equal to 40,50 and $17 \mu \mathrm{m}$, respectively. For each system, the laser power was set in the range of 0.01-1.5 W and the scanning speed was fixed at $5 \mathrm{~mm} / \mathrm{s}$.

The relative enhancement in the XRD peak intensity, $I_{R}$, can be quantified as

$$
I_{R}=\left(I-I_{o}\right) / I_{0},
$$

where $I_{R}$ is the relative enhancement in the XRD peak intensity, $\mathrm{I}$ is the intensity following laser treatment, $\mathrm{I}_{\mathrm{o}}$ is the initial intensity.

The surface morphologies of the various samples were observed using a field emission scanning electron microscope (FESEM, JSM-7600F). Moreover, the microstructures of the samples were examined using an X-ray Diffractometer (Bruker D8) with $\mathrm{Cu}-\mathrm{Ka}$ radiation. The optical transmittance was measured using a UV-VISIR spectrophotometer (Lambda 35). Finally, the frequency response of the SMR filters was measured using a network analyzer (E5071C) and a CASCADE high-frequency probe (RHM-06/V + GSG 150).

\section{Results and discussions}

Figure 2 presents a cross-sectional SEM image of the asdeposited AlN film. As shown, the film has a thickness of approximately $1.3 \mu \mathrm{m}$. Figure 3 shows the XRD spectra of the as-deposited AlN film and the film annealed by these 


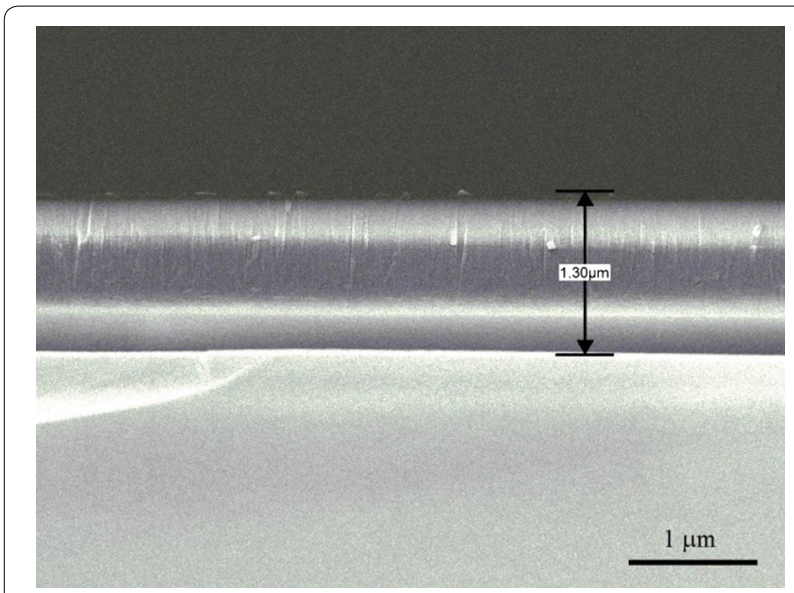

Fig. 2 SEM cross-sectional image of as-deposited AIN film laser systems. It is seen that the preferred (002) orientation of the AlN film is obtained in both samples. However, it is evident that the annealing process results in a significant increase in the (002) peak intensity. The UV annealing process increases the (002) peak intensity by $58.7 \%$ compared to that of the as-deposited AlN sample. The relative improvement for the Green and NIR system is seen to be $16.8 \%$ and $36.8 \%$, respectively.

Figure 4 shows the relative enhancement in the (002) peak intensity as a function of the laser power for all three laser systems. It is apparent that the effectiveness of the different laser systems in improving the crystal quality of the AlN film is extremely sensitive to the processing power. From inspection, the optimal powers of the UV $(355 \mathrm{~nm})$, Green $(532 \mathrm{~nm})$ and NIR $(1064 \mathrm{~nm})$ laser systems are equal to $0.025 \mathrm{~W}, 0.15 \mathrm{~W}$ and $0.25 \mathrm{~W}$, respectively. Given these values of the laser power, the relative improvement in the (002) peak intensity is seen to be $58.7 \%, 16.8 \%$ and $36.8 \%$, respectively. Figure 5 presents SEM images of the as-deposited AlN film and the AlN films processed by the UV laser with various powers. For laser powers lower than $0.05 \mathrm{~W}$, the AlN film has a dense microstructure with a strong c-axis orientation. In other words, a recrystallization of the as-deposited film occurs following the laser treatment process. However, for powers greater than $0.1 \mathrm{~W}$, the AlN films have a cracked and rough surface due to the ablation effect caused by the higher thermal input energy. As a result, the (002) peak intensity of the AlN film is significantly reduced, as shown in Fig. 4.

Figure 6 shows the reflectance spectrum of the asdeposited AlN film. From inspection, the reflectance values of the AlN films processed using the NIR, Green and UV laser systems are 61, 51 and $46 \%$, respectively. In other words, the absorption of the AlN film increases with a decreasing wavelength. It is noted that this finding is consistent with the results presented in Fig. 4,
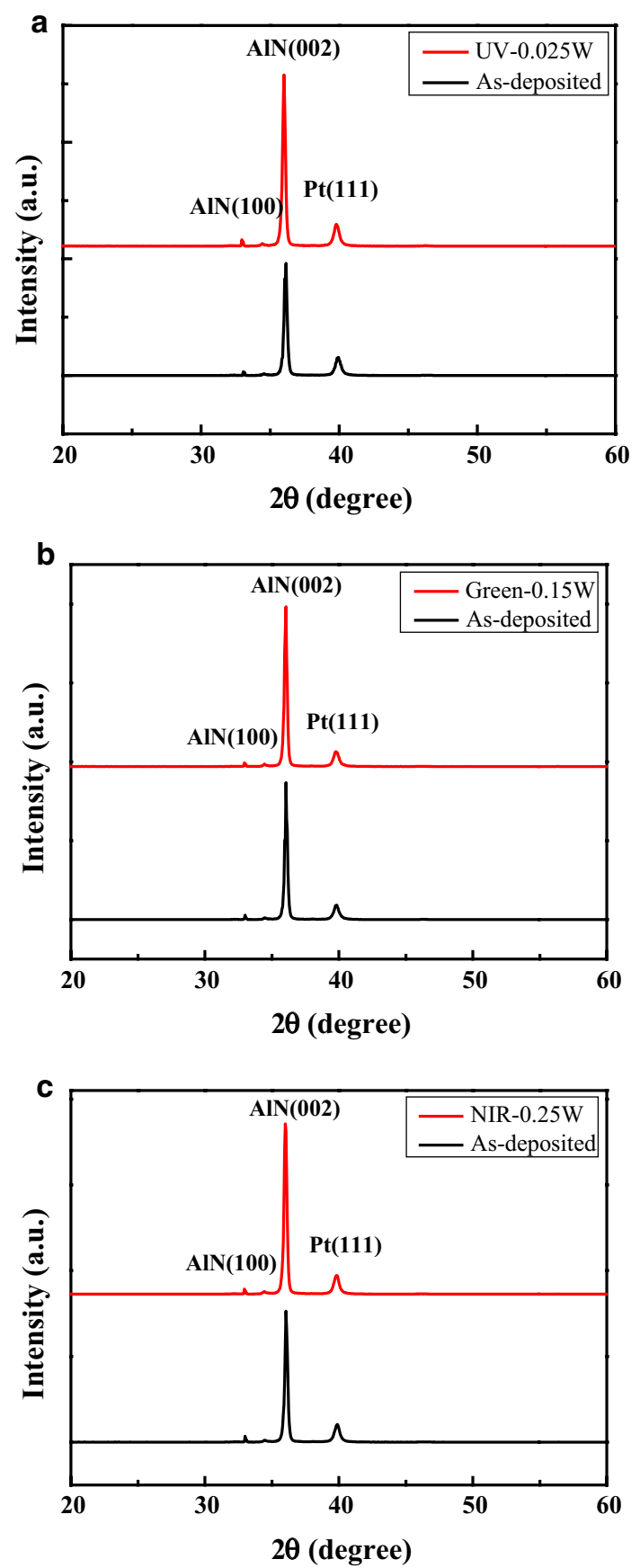

Fig. 3 XRD profiles of as-deposited AIN film and AIN film annealed using three laser systems: $\mathbf{a} \cup V, \mathbf{b}$ green and $\mathbf{c}$ NIR

which show that the optimal power $(0.025 \mathrm{~W})$ for the UV system (wavelength $355 \mathrm{~nm}$ ) is lower than that $(0.25 \mathrm{~W})$ of the NIR laser system (wavelength $1064 \mathrm{~nm})$. Figure 7 shows the center frequency response of two SMR filters containing an as-deposited AlN film and 


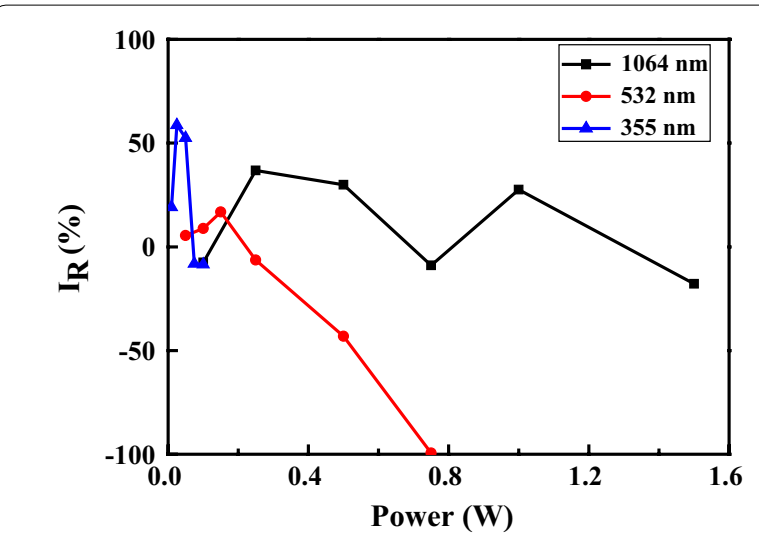

Fig. 4 Relative improvement in (002) peak intensity as function of laser power for laser systems with different wavelengths

an AlN film annealed using the NIR laser system with a power of $0.25 \mathrm{~W}$, respectively. The SMR filter containing an unprocessed AlN film has a resonant frequency of $2850 \mathrm{MHz}$. However, following laser irradiation, the resonant frequency increased to $2858 \mathrm{MHz}$, while the frequency of $3 \mathrm{~dB}$ bandwidth changes from 227.81 to 202.49 MHz. In addition, the return loss of the SMR filter decreases from $16.48 \mathrm{~dB}$ in the untreated condition to $17.28 \mathrm{~dB}$ in the annealed condition as a result of the improved crystalline quality of the AlN film. Overall, the results show that the resonant frequency and return loss of the SMR filter can both be adjusted through the use of an appropriate laser treatment process.

\section{Conclusions}

AlN films have been deposited on Si substrates using a reactive sputtering process. The AlN films have been laser annealed with various laser powers and wavelengths. The XRD results have shown that the laser annealing process yields an effective improvement in the (002) peak intensity of the AlN film. For irradiation wavelengths of 355, 532 and $1064 \mathrm{~nm}$, the optimal laser power has been found to be $0.025,0.15$ and $0.25 \mathrm{~W}$, respectively. The corresponding enhancement in the (002) peak intensity is equal to $58.7 \%, 16.8 \%$ and $36.8 \%$, respectively. For a SMR filter with an as-deposited AlN film, the resonant frequency is equal to $2850 \mathrm{MHz}$ and the $3 \mathrm{~dB}$ bandwidth is 227.81. Following laser treatment with a wavelength of $1064 \mathrm{~nm}$ and a power of $0.25 \mathrm{~W}$, the resonant frequency increases to $2858 \mathrm{MHz}$. In addition, the $3 \mathrm{~dB}$ bandwidth reduces to $202.49 \mathrm{MHz}$ and the return loss reduces from 17.28 to $16.48 \mathrm{~dB}$. In other
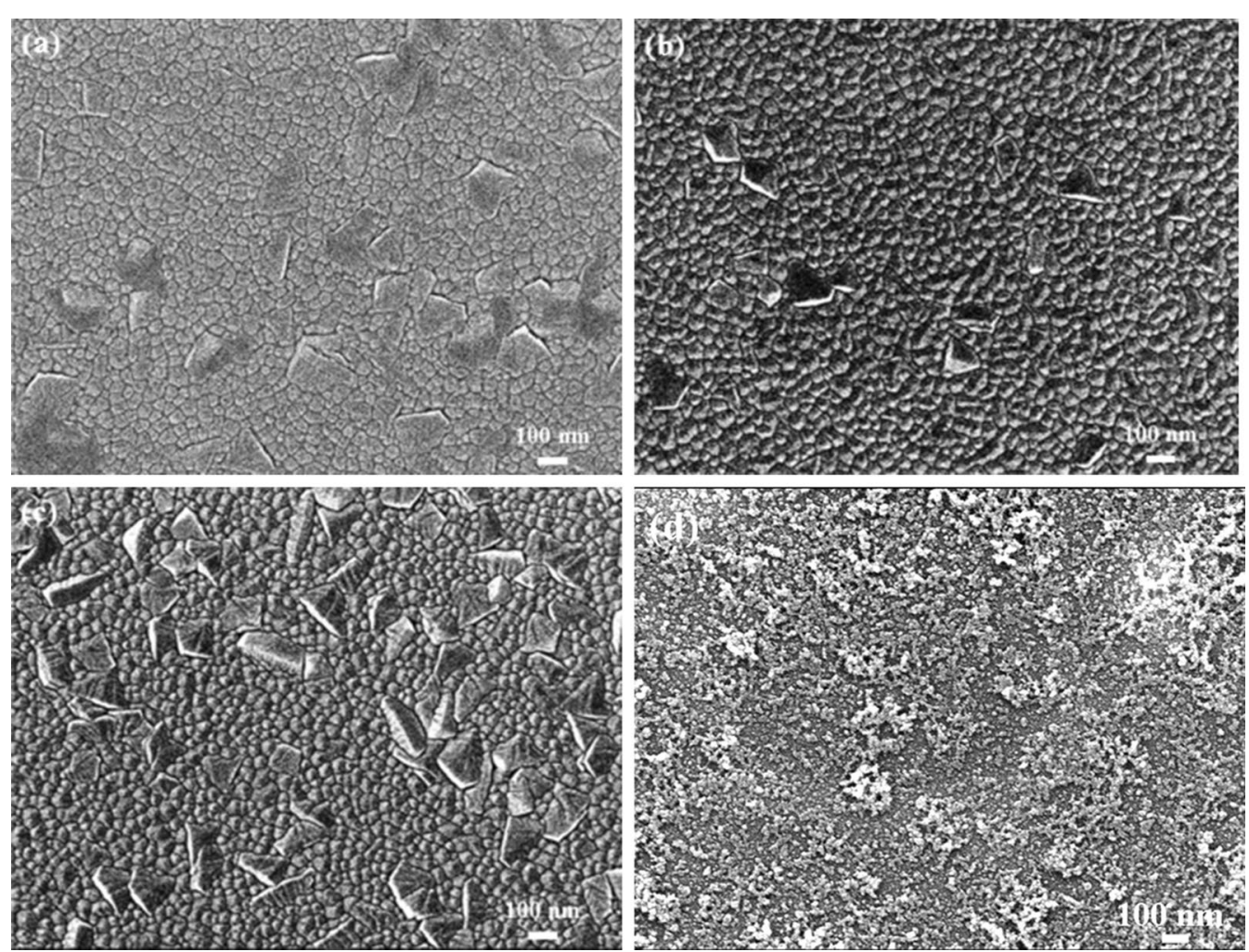

Fig. 5 SEM images of as-deposited and UV-annealed AIN films: a as-deposited, b 0.025 W, c 0.05 W and d 0.1 W 


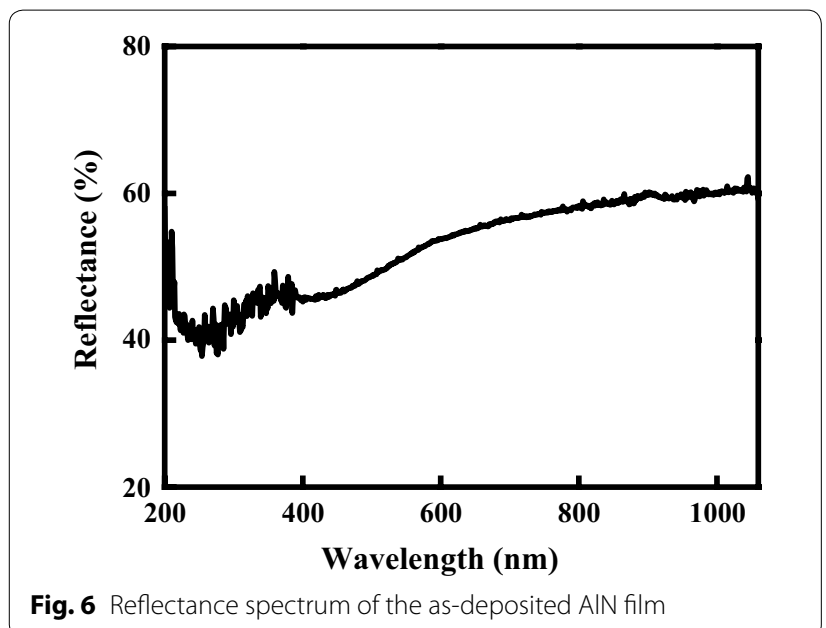

Fig. 6 Reflectance spectrum of the as-deposited AIN film

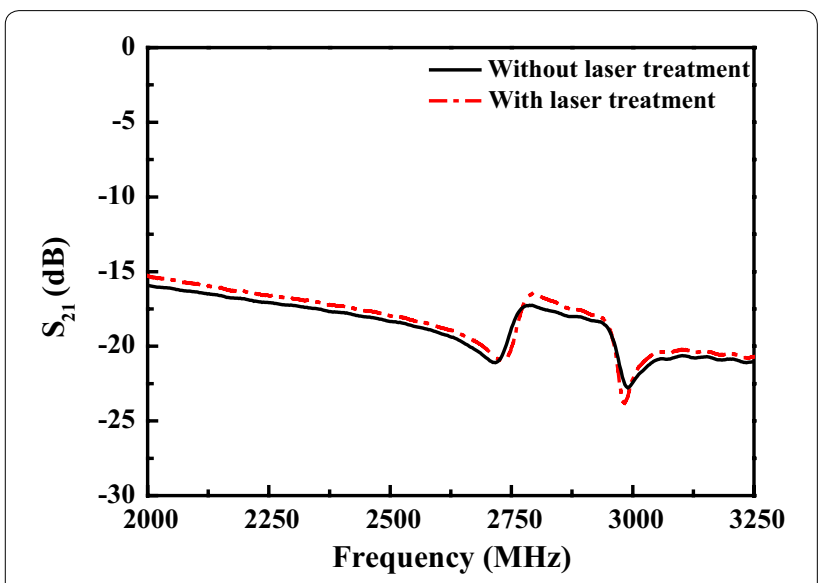

Fig. 7 Resonant frequency of SMR filters with as-deposited and annealed AIN films

words, the resonant frequency of the SMR filter can be tuned and the return loss reduced through the use of a laser irradiation process with appropriate wavelength and power settings.

\section{Authors' contributions}

HKL conceived of the study, and participated in its design and coordination and drafted the manuscript. YJH carried out the laser and film studies. WCS prepared the AIN film and solidly mounted resonators. YCC participated in the design of the resonator and helped to draft the manuscript. WTC did some microstructure experiments. All authors discussed the results and commented on the manuscript. All authors read and approved the final manuscript.

\section{Author details}

${ }^{1}$ Graduate Institute of Materials Engineering, National Pingtung University of Science and Technology, Pingtung, Taiwan. ${ }^{2}$ Department of Electrical Engineering, National Sun Yat-Sen University, Kaohsiung, Taiwan. ${ }^{3}$ Metal Industries Research \& Development Centre, Kaohsiung, Taiwan.

\section{Acknowledgements}

The authors gratefully acknowledge the financial support provided to this study by the Ministry of Science and Technology of Taiwan under Grant Nos. MOST 105-2221-E-020-007 and 104-2221-E-020-007.

\section{Competing interests}

The authors declare that they have no competing interests.

\section{Availability of data and materials}

The raw/processed data required to reproduce these findings cannot be shared at this time as the data also forms part of an ongoing study.

\section{Funding}

Not applicable.

\section{Publisher's Note}

Springer Nature remains neutral with regard to jurisdictional claims in published maps and institutional affiliations.

Received: 22 October 2018 Accepted: 6 March 2019

Published online: 16 March 2019

\section{References}

1. Colin KC (1989) Applications of surface acoustic and shallow bulk acoustic wave devices. Proc IEEE 77:1453-1484

2. Lange K, Rapp BE, Rapp M (2008) Surface acoustic wave biosensors: a review. Anal Bioanal Chem 391(5):1509-1519

3. Afzal A, lqbal N, Mujahid A, Schirhagl R (2013) Advanced vapor recognition materials for selective and fast responsive surface acoustic wave sensors: a review. Anal Chim Acta 787:36-49

4. Serhane R, Abdelli-Messaci S, Lafane S, Khales H, Aouimeur W, HasseinBey A, Boutkedjirt T (2014) Pulsed laser deposition of piezoelectric ZnO thin films for bulk acoustic wave devices. Appl Surf Sci 288:572-578

5. Zhang X, Xu WC, Chae J (2011) Temperature effects on a high Q FBAR in liquid. Sensor Actuators A Phys 166(2):264-268

6. Lin RC, Chen YC, Chang WT, Cheng CC, Kao KS (2008) Highly sensitive mass sensor using film bulk acoustic resonator. Sens Actuators A 147(2):425-429

7. Sharma G, Liljeholm L, Enlund J, Bjurström J, Katardjiev I, Hjort K (2010) Fabrication and characterization of a shear mode AIN solidly mounted resonator-silicone microfluidic system for in-liquid sensor applications. Sens Actuators A 159(1):111-116

8. Chen D, Xu Y, Wang J, Zhang L, Wang X, Liang M (2010) The AIN based solidly mounted resonators consisted of the all-metal conductive acoustic Bragg reflectors. Vacuum 85(2):302-306

9. García-Gancedo L, Pedrós J, Iborra E, Clement M, Zhao XB, Olivares J, Capilla J, Luo JK, Lu JR, Milne WI, Flewitt AJ (2013) Direct comparison of the gravimetric responsivities of ZnO-based FBARs and SMRs. Sens Actuators B Chem 183:136-143

10. Hong HS, Chung GS (2010) Humidity sensing characteristics of Ga-doped zinc oxide film grown on a polycrystalline AIN thin film based on a surface acoustic wave. Sens Actuators B Chem 150(2):681-685

11. Kale A, Brusa RS, Miotello A (2012) Structural and electrical properties of AlN films deposited using reactive RF magnetron sputtering for solar concentrator application. Appl Surf Sci 258(8):3450-3454

12. Phan DT, Chung GS (2011) The effect of geometry and post-annealing on surface acoustic wave characteristics of AIN thin films prepared by magnetron sputtering. Appl Surf Sci 257(20):8696-8701

13. Claudel A, Blanquet E, Chaussende D, Boichot R, Doisneau B, Berthomé $G$, Crisci A, Mank H, Moisson C, Pique D, Pons M (2011) Investigation on AIN epitaxial growth and related etching phenomenon at high temperature using high temperature chemical vapor deposition process. J Cryst Growth 335(1):17-24

14. Stan GE, Botea M, Boni GA, Pintilie I, Pintilie L (2015) Electric and pyroelectric properties of AIN thin films deposited by reactive magnetron sputtering on Si substrate. Appl Surf Sci 353:1195-1202

15. Liu B, Gao J, Wu KM, Liu C (2009) Preparation and rapid thermal annealing of AlN thin films grown by molecular beam epitaxy. Solid State Commun 149:715-717

16. Jacquot A, Lenoir B, Dauscher A, Verardi P, Cracium F, Stolzer M, Gartner M, Dinescu M (2002) Optical and thermal characterization of AIN thin films deposited by pulsed laser deposition. Appl Surf Sci 186:507-512 
17. Kar JP, Bose G, Tuli S (2005) Influence of rapid thermal annealing on morphological and electrical properties of RF sputtered AIN films. Mater Sci Semicond Process 8(6):646-651

18. Vergara L, Olivares J, Iborra E, Clement M, Sanz-Hervás A, Sangrador $J$ (2006) Effect of rapid thermal annealing on the crystal quality and the piezoelectric response of polycrystalline AIN films. Thin Solid Films 515(4):1814-1818

19. Lee E, Ruirui Z, Yoon G (2011) Nitrogen [N]-incorporated ZnO piezoelectric thin films and their application for ultra-small film bulk acoustic wave resonator device fabrication. J Appl Phys 110:074101-074101.7

20. Lin CH, Yamashita Y, Miyake H, Hiramatsu K (2017) Fabrication of highcrystallinity a-plane AIN films grown on r-plane sapphire substrates by modulating buffer-layer growth temperature and thermal annealing conditions. J Cryst Growth 468:845-850

21. Jo M, Itokazu Y, Kuwaba S, Hirayama H (2019) Improved crystal quality of semipolar AIN by employing a thermal annealing technique with MOVPE. J Cryst Growth 507:307-309
22. Ababneh A, Schmid U, Hernando J, Sánchez-Rojas JL, Seidel H (2010) The influence of sputter deposition parameters on piezoelectric and mechanical properties of AIN thin films. Mater Sci Eng B 172(3):253-258

23. Lin HK, Cheng KC, Huang JC (2015) Effects of laser annealing parameters on optical and electrical properties of ITO/metallic glass alloy Bi-layer films. Nanoscale Res Lett 10(1):982

24. Sadrnezhaad SK, Yasavol N, Ganjali M, Sanjabi S (2012) Property change during nanosecond pulse laser annealing of amorphous NiTi thin fil. Bull Mater Sci 35:357-364

25. Cheng CC, Lin RC, Lin HK, Kao KS, Chen YC (2016) Frequency modulation and device repaired by laser surface treatment in film bulk acoustic filters. J Laser Micro/Nanoeng 11(1):13-16
Ready to submit your research? Choose BMC and benefit from:

- fast, convenient online submission

- thorough peer review by experienced researchers in your field

- rapid publication on acceptance

- support for research data, including large and complex data types

- gold Open Access which fosters wider collaboration and increased citations

- maximum visibility for your research: over $100 \mathrm{M}$ website views per year

At BMC, research is always in progress.

Learn more biomedcentral.com/submissions 